\title{
The amygdala is critical for trace, delay, and contextual fear conditioning
}

\author{
Daniel E. Kochli, Elaine C. Thompson, Elizabeth A. Fricke, Abagail F. Postle, \\ and Jennifer J. Quinn \\ Department of Psychology and Center for Neuroscience and Behavior, Miami University, Oxford, Ohio 45056, USA
}

\begin{abstract}
Numerous investigations have definitively shown amygdalar involvement in delay and contextual fear conditioning. However, much less is known about amygdala contributions to trace fear conditioning, and what little evidence exists is conflicting as noted in previous studies. This discrepancy may result from selective targeting of individual nuclei within the amygdala. The present experiments further examine the contributions of amygdalar subnuclei to trace, delay, and contextual fear conditioning. Rats were trained using a 10-trial trace, delay, or unpaired fear conditioning procedure. Pretraining lesions targeting the entire basolateral amygdala (BLA) resulted in a deficit in trace, delay, and contextual fear conditioning. Immediate post-training infusions of the protein synthesis inhibitor, cycloheximide, targeting the basal nucleus of the amygdala (BA) attenuated trace and contextual fear memory expression, but had no effect on delay fear conditioning. However, infusions targeting the lateral nucleus of the amygdala (LA) immediately following conditioning attenuated contextual fear memory expression, but had no effect on delay or trace fear conditioning. In follow-up experiments, rats were trained using a three-trial delay conditioning procedure. Immediate post-training infusions targeting the LA produced deficits in both delay tone and context fear, while infusions targeting the BA produced deficits in context but not delay tone fear. These data fully support a role for the BLA in trace, delay, and contextual fear memories. Specifically, these data suggest that the BA may be more critical for trace fear conditioning, whereas the LA may be more critical for delay fear memories.
\end{abstract}

Pavlovian fear conditioning is one of the most extensively studied systems for investigating the neural mechanisms mediating learning and memory processes. It is a behavioral paradigm in which an organism learns to anticipate an aversive event by pairing that event (i.e., unconditioned stimulus; US) with a particular place or predictive stimulus (i.e., conditioned stimulus; CS). The amygdala serves a critical role in this fear learning; it receives both unimodal and multimodal sensory information and projects to a number of individual response circuits allowing for a coordinated fear response (e.g., Davis 1997, 2006; Fanselow and LeDoux 1999; Lee et al. 2001). More specifically, CS (e.g., tone, context) and US (e.g., footshock) sensory inputs converge in the basolateral amygdala (BLA) where the CS-US association is formed (Barot et al. 2009). Formation of this association requires protein synthesis in the amygdala (e.g., Bailey et al. 1999; Schafe and LeDoux 2000; Maren et al. 2003; Kwapis et al. 2011). Once formed, this BLA-dependent association permanently supports the expression of fear memory (LeDoux 1993; Fanselow and LeDoux 1999; Gale et al. 2004; Davis 2006; Amano et al. 2011). The BLA projects, both directly and indirectly, to the central nucleus of the amygdala (CeA), which in turn projects to brainstem and hypothalamic regions to trigger individual fear responses (LeDoux et al. 1988; Wilensky et al. 2006; Amano et al. 2011; Viviani et al. 2011).

Typically, fear conditioning to an auditory stimulus is performed using a delay procedure in which tone and footshock are temporally contiguous. There is a wealth of experiments that have demonstrated that this type of learning depends on the amygdala (e.g., Fanselow and LeDoux 1999). Trace fear conditioning differs from delay conditioning in that a stimulus-free trace in-

Corresponding author: quinnjj@miamioh.edu

Article is online at http://www.learnmem.org/cgi/doi/10.1101/Im.034918.114. terval is inserted between the termination of the tone and the onset of footshock. Unlike delay conditioning (but see Quinn et al. 2008, 2009; Maren 2008), acquisition of trace fear conditioning is critically dependent on several other structures, such as the medial prefrontal cortex and the hippocampus (e.g., McEchron et al. 1998; Quinn et al. 2002, 2005, 2008; Han et al. 2003; Chowdhury et al. 2005; Gilmartin and McEchron 2005a,b; Gilmartin and Helmstetter 2010). Surprisingly, little is known about amygdalar contributions to trace fear conditioning, and the few published studies are conflicting (Kwapis et al. 2011; Raybuck and Lattal 2011; Gilmartin et al. 2012). Further, no studies have addressed possible differential contributions of amygdalar subnuclei to trace fear conditioning.

To further investigate the role of the amygdala in trace, delay, and contextual fear conditioning, we performed five experiments. In Experiment 1, rats received pretraining lesions of the basolateral amygdala (BLA) or sham surgery prior to 10-trial trace or delay fear conditioning. This allowed us to assess the collective contribution of the basal and lateral amygdalar nuclei to acquisition and/or expression of trace, delay, and simultaneously learned contextual fear conditioning. In Experiment 2, rats received bilateral infusions of the protein synthesis inhibitor, cycloheximide, or vehicle into the basal nucleus of the amygdala (BA) immediately following 10-trial trace or delay fear conditioning. This experiment allowed us to assess the role of de novo protein synthesis in $\mathrm{BA}$ in the consolidation of trace and delay fear conditioning, as well as simultaneously acquired contextual fear conditioning.

(C) 2015 Kochli et al. This article is distributed exclusively by Cold Spring Harbor Laboratory Press for the first 12 months after the full-issue publication date (see http://learnmem.cshlp.org/site/misc/terms.xhtml). After 12 months, it is available under a Creative Commons License (AttributionNonCommercial 4.0 International), as described at http://creativecommons .org/licenses/by-nc/4.0/. 
Experiment 3 was identical to Experiment 2 except that infusions targeted the LA. In Experiment 4, rats received bilateral infusions of cycloheximide or vehicle into the BA immediately following three-trial delay conditioning. Experiment 5 was identical to Experiment 4 except that infusions targeted the LA. Experiments 4 and 5 allowed us to address the role of training strength/session duration in the effects of cycloheximide on the consolidation of delay fear conditioning.

\section{Results}

\section{Experiment 1: basolateral amygdalar lesions disrupt tone and context fear memory in trace and delay conditioned rats}

Prior to trace or delay fear conditioning, rats received bilateral neurotoxic lesions of the basolateral amygdala. Tests for freezing to both tone and context occurred across two consecutive days following training (see Fig. 1A).

\section{Verification of lesions}

Lesion extent was quantified in a manner similar to that described previously (Quinn et al. 2013). Briefly, three brain slices throughout the extent of the BLA were stained using immunofluorescence for NeuN and GFAP. Lesion extent was visualized via fluorescent microscopy, and was quantified using ImageJ (NIH) software. Five rats were excluded from statistical analyses; four cases were excluded due to unilateral lesions, and one case was excluded due to lesion misplacement. The lesion extents of the remaining 31 rats were deemed acceptable and included in all statistical analyses (see Fig. 1B). Overall, lesion extent covered 53\% of the BLA, with trace animals averaging 59\% and delay animals averaging $47 \%$. Lesion extents were primarily confined to the BLA, but seven cases extended laterally into adjacent temporal cortices (five trace, two delay) and six cases extended medially into the lateral portion of the CeA (four trace, two delay). Additionally, eight cases had at least unilateral sparing of the most anterior portion of the BLA (four traces, four delays).

\section{Tone test}

Despite very low levels of freezing during the 180-sec baseline period of the tone test, there was a significant main effect of surgery $\left[F_{(1,27)}=6.17, P<0.05\right]$, but no main effect of training $\left[F_{(1,27)}>\right.$ $0.01, P=0.973]$ and no training $\times$ surgery interaction $\left[F_{(1,27)}=\right.$ $0.40, P=0.531]$. However, pairwise comparisons within each training condition revealed no differences between lesion and sham rats $(P>0.05$; Fig. $1 C)$.

During the tone (averaged across the three presentations), there was a significant main effect of training $\left[F_{(1,27)}=16.17\right.$, $P<0.001]$, a significant main effect of surgery $\left[F_{(1,27)}=73.82\right.$, $P<0.001]$, but no training $\times$ surgery interaction $\left[F_{(1,27)}=0.04\right.$, $P=0.844]$. Delay conditioned animals froze significantly more than trace conditioned animals. Further, both trace and delay lesioned animals showed a significant deficit in freezing to tone compared with their corresponding sham controls $(P<0.05$; Fig. 1C).

During the trace interval (or trace interval equivalent for delay animals), there was a significant main effect of surgery $\left[F_{(1,27)}=195.02, \quad P<0.001\right]$, but no main effect of training $\left[F_{(1,27)}=2.29, P=0.142\right]$ and no training $\times$ surgery interaction $\left[F_{(1,27)}=0.04, P=0.841\right]$. Following both trace and delay conditioning, lesion rats froze significantly less than shams during the 28-sec period following the tone ( $P<0.05$; Fig. 1C).

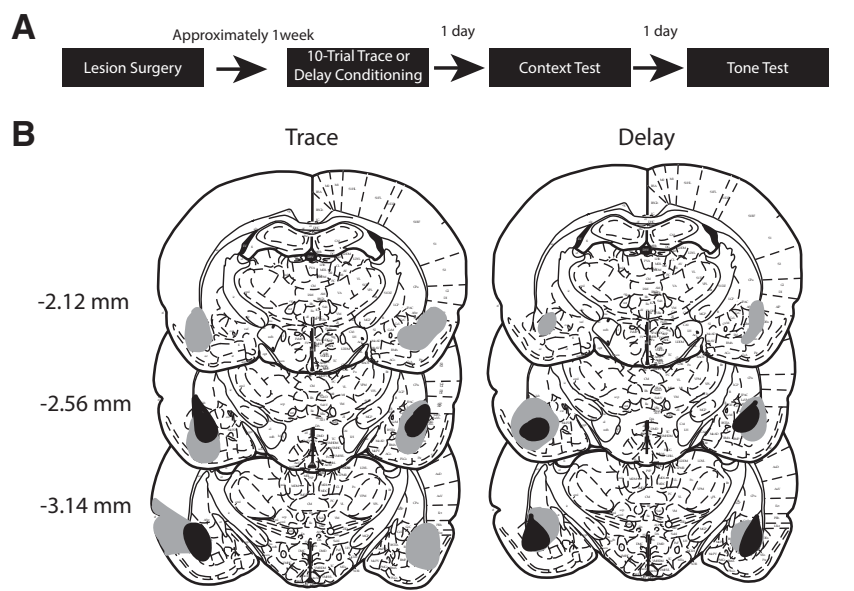

C Tone Test
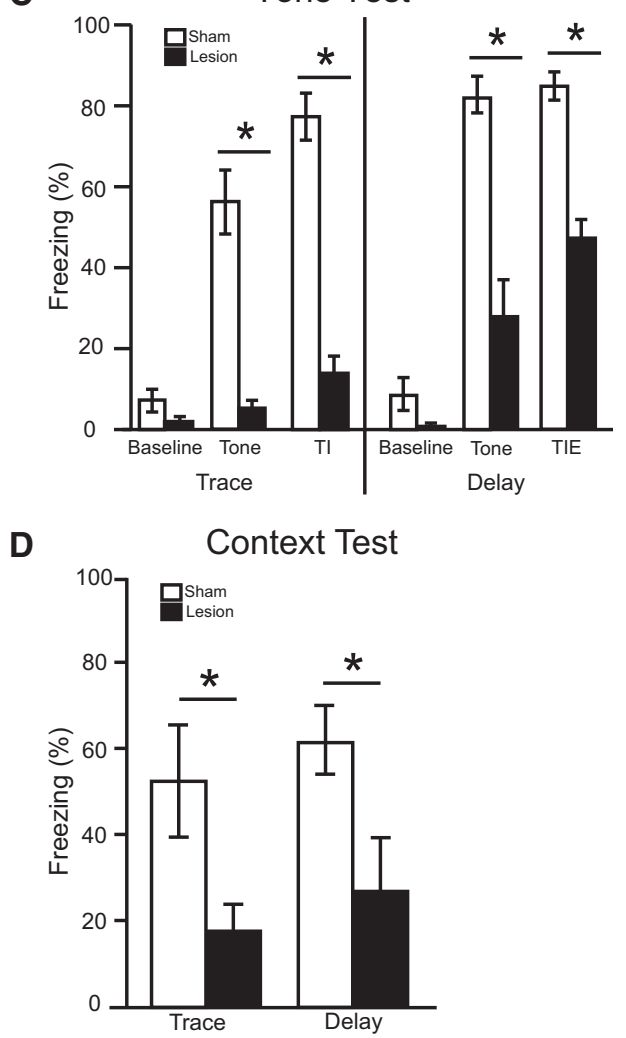

Figure 1. (A) Timeline for Experiment 1. (B) The minimum (black) and maximum (gray) extent of bilateral lesions in BLA (atlas images taken and modified from Paxinos and Watson 1998 with permission from Elsevier 1998). The number of animals in each group was as follows: trace sham, $n=7$; trace lesion, $n=7$; delay sham, $n=8$; delay lesion, $n=9$; $N=31$. (C) The percentage of time spent freezing during the baseline period (first $3 \mathrm{~min}$ ), tone, and trace interval or trace interval equivalent during the tone test. $(D)$ Simultaneously learned contextual fear expressed during the context test.

\section{Context test}

The average percentage of time spent freezing over the entire $8 \mathrm{~min}$ of the context test was calculated (Fig. 1D). There was a significant main effect of surgery $\left[F_{(1,27)}=11.41, P<0.01\right]$, but no main effect of training $\left[F_{(1,27)}=0.82, P=0.372\right]$ and no training $\times$ surgery interaction $\left[F_{(1,27)}<0.01, P=0.975\right]$. Following both trace 
and delay conditioning, lesion rats froze significantly less than sham rats during the context test $(P<0.05)$.

\section{Experiment 2: basal amygdalar protein synthesis is necessary for the consolidation of trace and contextual conditioned fear memory}

Immediately following trace, delay, or unpaired fear conditioning, rats received bilateral infusions of either cycloheximide or vehicle targeting the basal nucleus of the amygdala. Over the next $2 \mathrm{~d}$, rats were tested for freezing to both tone and context in separate sessions (see Fig. 2A).
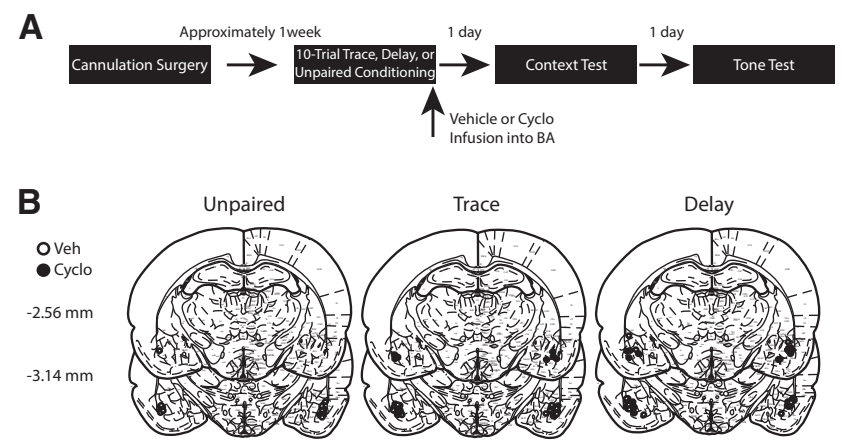

C

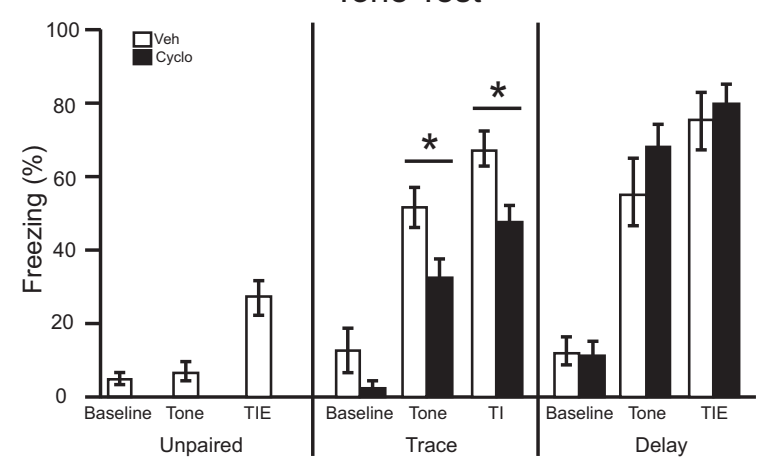

D

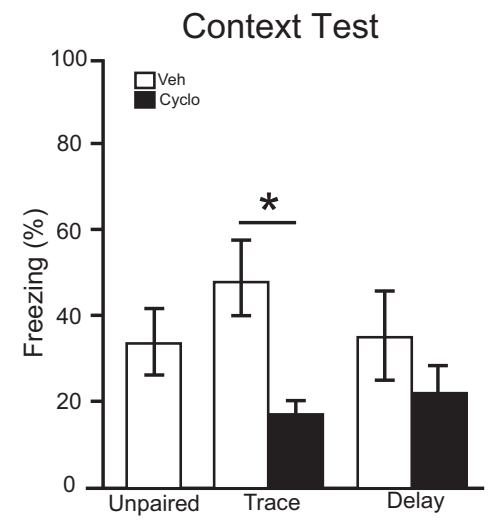

Figure 2. (A) Timeline for Experiment 2. (B) Cannula placement for all animals included in Experiment 2 (atlas images taken and modified from Paxinos and Watson 1998 with permission from Elsevier 1998). The number of animals in each group was as follows: unpaired veh, $n=9$, trace veh, $n=11$; trace cyclo, $n=11$; delay veh, $n=10$; delay cyclo, $n=10 ; N=51$. (C) The percentage of time spent freezing during baseline period (first $3 \mathrm{~min}$ ), tone, and trace interval or trace interval equivalent during the tone test. $(D)$ Simultaneously learned contextual fear expressed during the context test.

\section{Verification of infusion location}

Brains were sliced and stained with cresyl violet to verify cannulae placements. Three rats were excluded from statistical analysis due to misplaced cannulae. The cannulae placements in the remaining 51 rats were deemed acceptable and included in all statistical analyses (see Fig. 2B).

\section{Tone test}

During the 180-sec baseline period of the tone test, no differences were observed among groups $\left[F_{(4,46)}=1.58, P=0.195\right]$. Further, among trace and delay conditioned animals, there were no main effects of training $\left[F_{(1,38)}=1.01, P=0.322\right]$ or infusion $\left[F_{(1,38)}=1.88, P=0.178\right]$ and no interaction $\left[F_{(1,38)}=1.26, P=\right.$ 0.268] (Fig. 2C).

Average freezing during the test tones was significantly different in vehicle-infused rats as a function of training condition $\left[F_{(2,27)}=16.04, P<0.001\right]$. Pairwise comparisons revealed that both trace and delay vehicle-infused rats froze significantly more than unpaired controls $(P<0.05)$, demonstrating that the freezing in trace and delay animals results from associative processes. Among trace and delay conditioned rats, there was a significant main effect of training $\left[F_{(1,38)}=9.78, P<0.01\right]$, and a significant training $\times$ infusion interaction $\left[F_{(1,38)}=6.37, P<\right.$ $0.05]$, but no main effect of infusion $\left[F_{(1,38)}=0.28, P=0.598\right]$. Pairwise comparisons revealed a significant deficit in tone freezing for cycloheximide infusions in trace, but not delay, conditioned animals (Fig. 2C).

During the trace interval (or trace interval equivalent for unpaired and delay conditioned animals), freezing differed significantly in vehicle-infused rats as a function of training condition $\left[F_{(2,27)}=17.42, P<0.001\right]$. Pairwise comparisons revealed that both trace and delay vehicle-infused rats froze significantly more than unpaired controls $(P<0.05)$, showing that the freezing during this period continues to be a result of associative learning. Among trace and delay conditioned rats, there was a significant main effect of training $\left[F_{(1,38)}=12.61, P=0.001\right]$, and a significant training $\times$ infusion interaction $\left[F_{(1,38)}=4.77, P<0.05\right]$, but no main effect of infusion $\left[F_{(1,38)}=1.75, P=0.194\right]$. Pairwise comparisons revealed a significant deficit in trace interval freezing for cycloheximide infusions in trace, but not delay, conditioned animals (Fig. 2C).

\section{Context test}

The average percentage of time spent freezing over the entire $8 \mathrm{~min}$ of the context test was calculated (Fig. 2D). Among vehicle-infused rats, there were no significant differences in context freezing as a function of training $\left[F_{(2,27)}=0.76, P=0.478\right]$. In trace and delay conditioned animals, there was a significant main effect of infusion $\left[F_{(1,38)}=8.65, P<0.05\right]$, but no main effect of training $\left[F_{(1,38)}=0.26, P=0.613\right]$ and no training $\times$ infusion interaction $\left[F_{(1,38)}=1.31, P=0.259\right]$. A priori planned comparisons revealed that cycloheximide infusions following trace conditioning attenuated freezing compared with vehicle infusions $[P<0.05]$. However, following delay conditioning, cycloheximide had no significant effect on context freezing $[P>0.05]$.

\section{Experiment 3: lateral amygdalar protein synthesis is necessary for the consolidation of context conditioned fear memory}

Immediately following trace or delay fear conditioning, rats received bilateral infusions of either cycloheximide or vehicle targeting the basal nucleus of the amygdala. Over the next $2 \mathrm{~d}$, rats 
were tested for freezing to both tone and context in separate sessions (see Fig. 3A).

\section{Verification of infusion location}

Brains were sliced and stained with cresyl violet to verify cannulae placements. Fifteen rats were excluded from statistical analysis due to misplaced cannulae. The cannulae placements in the remaining 35 rats were deemed acceptable and included in all statistical analyses (see Fig. 3B).

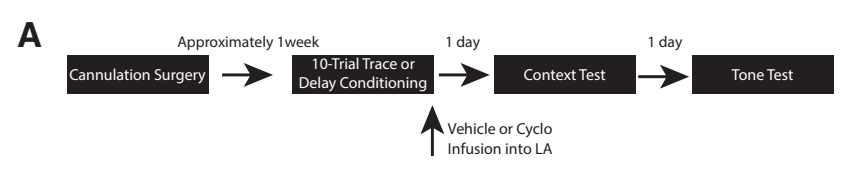

B

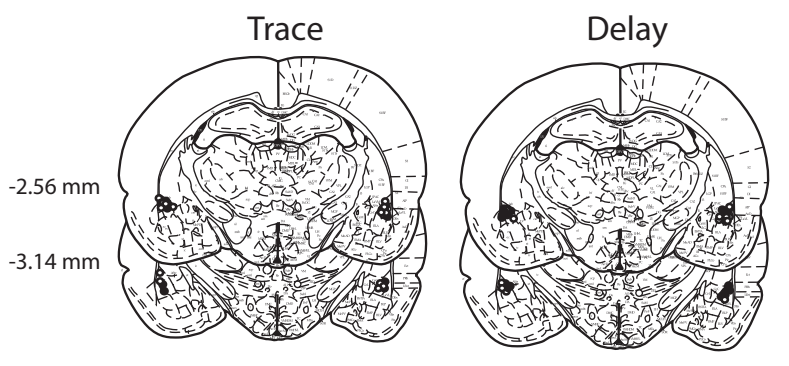

C
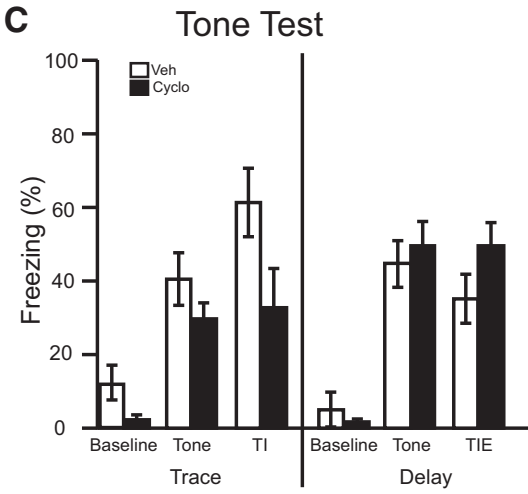

D

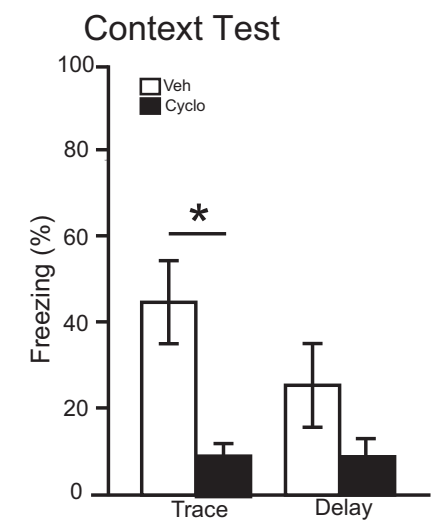

Figure 3. (A) Timeline for Experiment 3. (B) Cannula placement for all animals included in Experiment 3 (atlas images taken and modified from Paxinos and Watson 1998 with permission from Elsevier 1998). The number of animals in each group was as follows: trace veh, $n=8$; trace cyclo, $n=8$; delay veh, $n=9$; delay cyclo, $n=10 ; N=35$. (C) The percentage of time spent freezing during the baseline period (first $3 \mathrm{~min}$ ), tone, and trace interval or trace interval equivalent during the tone test. (D) Simultaneously learned contextual fear expressed during the context test.
Tone test

During the 180-sec baseline period of the tone test, no differences were observed among groups $\left[F_{(3,31)}=2.08, P=0.123\right]$. Further, among trace and delay conditioned animals, there were no main effects of training $\left[F_{(1,31)}=1.34, P=0.255\right]$ or infusion $\left[F_{(1,31)}=4.06, P=0.053\right]$ and no interaction $\left[F_{(1,31)}=1.09, P=\right.$ 0.304] (Fig. 3C).

During the tone period of the tone test, no differences were observed among groups $\left[F_{(3,31)}=1.99, P=0.137\right]$. Further, there were no main effects of training $\left[F_{(1,31)}=3.83, P=0.059\right]$ or infusion $\left[F_{(1,31)}=0.36, P=0.555\right]$ and no interaction $\left[F_{(1,31)}=1.80\right.$, $P=0.189]$ (Fig. 3C).

Similarly, during the trace interval or trace interval equivalent period of the tone test, no differences were observed among groups $\left[F_{(3,31)}=2.5, P=0.077\right]$. Further, there were no main effects of training $\left[F_{(1,31)}=0.36, P=0.551\right]$ or infusion $\left[F_{(1,31)}=\right.$ $0.77, P=0.338]$. However, a significant training $\times$ infusion interaction was revealed $\left[F_{(1,31)}=6.78, P<0.05\right]$ (Fig. 3C). An a priori planned comparison revealed that trace conditioned animals infused with cycloheximide trended toward differing from vehicle controls, but did not reach significance $[P=0.062]$.

\section{Context test}

The average percentage of time spent freezing over the entire $8 \mathrm{~min}$ of the context test was calculated (Fig. 3D). Among vehicle-infused rats, there were no significant differences in context freezing as a function of training $\left[F_{(1,15)}=1.98, P=0.180\right]$. In trace and delay conditioned animals, there was a significant main effect of infusion $\left[F_{(1,31)}=12.98, P<0.001\right]$, but no main effect of training $\left[F_{(1,31)}=1.81, P=0.198\right]$ and no training $\times$ infusion interaction $\left[F_{(1,31)}=1.76, P=0.195\right]$. A priori planned comparisons revealed that cycloheximide infusions following trace conditioning attenuated freezing compared with vehicle infusions $[P<0.01]$. However, following delay conditioning, cycloheximide had no significant effect on context freezing $[P>0.05]$.

\section{Experiment 4: basal amygdalar protein synthesis is necessary for the consolidation of contextual, but not 3-trial delay, conditioned fear memory}

Immediately following 3-trial delay fear conditioning, rats received bilateral infusions of either cycloheximide or vehicle targeting the basal nucleus of the amygdala. Over the next $2 \mathrm{~d}$, rats were tested for freezing to both tone and context in separate sessions (see Fig. 4A).

\section{Verification of infusion location}

Brains were sliced and stained using cresyl violet to verify cannulae placements. Two rats were excluded from statistical analysis due to misplaced cannulae. The cannulae placements in the remaining 22 rats were deemed acceptable and included in all statistical analyses (see Fig. 4B).

\section{Tone test}

During the 180 -sec baseline period of the tone test, no differences were observed among infusion groups $\left[t_{(20)}=0.90, P=0.38\right]$. In addition, no differences were observed between infusion groups during the tone $\left[t_{(20)}=1.11, P=0.28\right]$ (see Fig. $4 \mathrm{C}$ ).

\section{Context test}

The average percentage of time spent freezing over the entire 8 min of the context test was calculated (Fig. 4C). It was revealed 
A
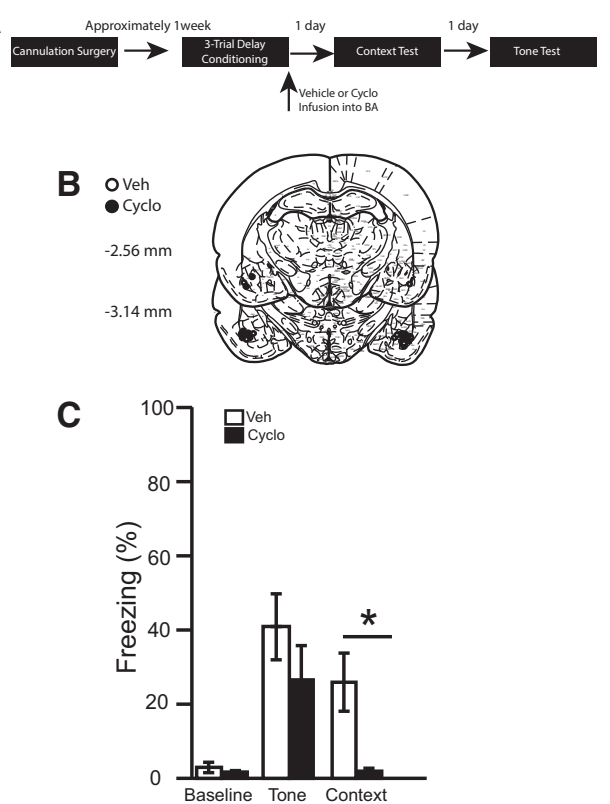

Figure 4. (A) Timeline for Experiment 4. (B) Cannula placement for all animals included in Experiment 4 (atlas images taken and modified from Paxinos and Watson 1998 with permission from Elsevier 1998). The number of animals in each group was as follows: delay veh, $n=11$; delay cyclo, $n=11 ; N=22$. (C) The percentage of time spent freezing during the baseline period (first $3 \mathrm{~min}$ ), tone, and context.

that post-training infusions of cycloheximide significantly attenuated freezing relative to controls $\left[t_{(20)}=3.04, P<0.01\right]$.

\section{Experiment 5: lateral amygdalar protein synthesis is necessary for the consolidation of three-trial delay and contextual conditioned fear memory}

Immediately following three-trial delay fear conditioning, rats received bilateral infusions of either cycloheximide or vehicle targeting the lateral nucleus of the amygdala. Over the next $2 \mathrm{~d}$, rats were tested for freezing to both tone and context in separate sessions (see Fig. 5A).

\section{Verification of infusion location}

Brains were sliced and stained with cresyl violet to verify cannulae placements. Four rats were excluded from statistical analysis due to misplaced cannulae. The cannulae placements in the remaining 20 rats were deemed acceptable and included in all statistical analyses (see Fig. 5B).

\section{Tone test}

During the 180 -sec baseline period of the tone test, no differences were observed among infusion groups $\left[t_{(18)}=1.843, P=0.08\right]$. It was revealed that post-training infusions of cycloheximide significantly attenuated freezing relative to controls during the tone, $\left[t_{(18)}=2.35, P<0.05\right]$ (see Fig. 5C).

\section{Context test}

The average percentage of time spent freezing over the entire 8 min of the context test was calculated (Fig. 5C). It was revealed that post-training infusions of cycloheximide significantly attenuated freezing relative to controls $\left[t_{(18)}=3.32, P<0.01\right]$.

\section{Discussion}

The present data provide strong support for the involvement of the basolateral amygdala in trace fear conditioning (see also Kwapis et al. 2011). Pretraining lesions of the BLA disrupt freezing to tone and context in both trace and delay conditioned animals. Post-training infusions of the protein synthesis inhibitor, cycloheximide, into the BA attenuate freezing during the tone, trace interval, and context test in trace conditioned rats. However, similar infusions into the BA had no significant effect on three- or 10-trial delay fear conditioning. By contrast, post-training infusions of cycloheximide into the LA disrupt three-trial delay and context freezing, but have no significant effect on trace or 10-trial delay fear memory consolidation. These data suggest that trace and delay fear conditioning may be differentially distributed in the BA and LA, respectively.

In the present series of experiments, 10 acquisition trials initially were used for both trace and delay fear conditioning. While 10 trials is typical for studies of trace fear conditioning in order to acquire a robust fear response to the tone, delay conditioning can be acquired using fewer tone-footshock pairings. Thus, 10 trials of delay conditioning yield very strong conditioning with asymptotic responding. It is possible that the lack of a deficit in cycloheximide-infused 10-trial delay conditioned animals (in Experiment 2) is a function of overtraining, rather than evidence of BA-independent delay conditioning. However, previous studies have shown that even animals given 75 overtraining trials using delay conditioning with an intact BLA subsequently display a significant deficit in freezing to the tone following BLA lesion or inactivation (Ponnusamy et al. 2007; Zimmerman et al. 2007). This suggests that in animals overtrained with intact basal and lateral nuclei of the amygdala, delay fear memory remains dependent upon those nuclei. However, due to the extended length of the training session in our 10-trial delay conditioning (45 min,

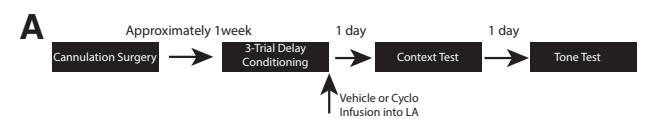

B

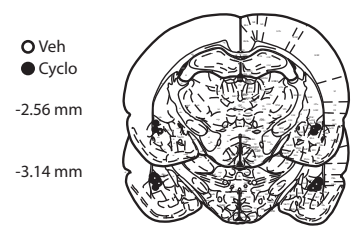

C

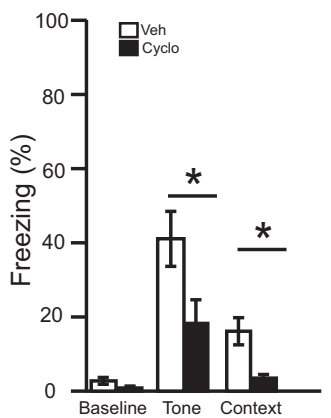

Figure 5. (A) Timeline for Experiment 5. (B) Cannula placement for all animals included in Experiment 5 (atlas images taken and modified from Paxinos and Watson 1998 with permission from Elsevier 1998). The number of animals in each group was as follows: delay veh, $n=10$; delay cyclo, $n=10 ; N=20$. (C) The percentage of time spent freezing during the baseline period (first $3 \mathrm{~min}$ ), tone, and context. 
$40 \mathrm{sec}$ ), it is possible that protein synthesis following the initial trials may occur prior to the infusion of cycloheximide that occurs following termination of the entire session. For this reason, a much shorter three-trial procedure with a much shorter session duration ( $6 \mathrm{~min}, 48 \mathrm{sec}$ ) was used in Experiments 4 and 5 . In these experiments, post-training cycloheximide infusions targeting the LA, but not BA, attenuated freezing to the tone. This is consistent with numerous previous reports of LA involvement in delay fear conditioning (Schafe and LeDoux 2000; Pape and Pare 2010; Kwapis et al. 2011).

Raybuck and Lattal (2011) demonstrated that muscimol inactivation of the amygdala impaired delay, but not trace, fear conditioning in mice. The discrepancy between their findings and ours (as well as those of Kwapis et al. 2011) might be explained by a number of differences in our approaches. The present study and Kwapis et al. (2011) used rats rather than mice. Additionally, these rat studies used more conditioning trials than did Raybuck and Lattal (2011), who used one, two, or four trials. However, this does not seem an entirely sufficient explanation as animals in all studies froze to the CS at reasonable levels during testing. The specific pharmacological manipulation may provide a better explanation. Raybuck and Lattal (2011) inactivated the amygdala using muscimol, while the present experiments and Kwapis et al. (2011) inhibited protein synthesis. As noted by Kwapis et al. (2011), protein synthesis and reconsolidation can take place in an inactivated amygdala under some conditions (e.g., Ben Mamou et al. 2006). As such, inactivation via muscimol may fail to prevent the consolidation of trace fear memory where protein synthesis inhibitors are effective. Additionally, it is possible that alternative mechanisms are able to compensate for the amygdala in trace fear conditioning that occurs when the amygdala is inactivated, as trace conditioning critically depends upon a number of other structures such as the hippocampus (e.g., Quinn et al. 2005) and medial prefrontal cortex (Gilmartin and Helmstetter 2010). Under some conditions, learning that is normally hippocampusdependent can be acquired via alternative mechanisms if the hippocampus has been inactivated (e.g., Rudy and O'Reilly 1999; Wiltgen et al. 2006). It is possible that the inactivation procedure used by Raybuck and Lattal (2011) facilitated the use of extra-amygdalar compensatory mechanisms, while protein synthesis inhibition used in the present experiment and by Kwapis et al. (2011) did not. Thus, amygdalar protein synthesis inhibition results in deficits in trace fear conditioning, while muscimol inactivation may not.

Some studies suggest that the BA is important in conditioned fear (e.g., Sananes and Davis 1992) and, more specifically, delay fear conditioning (Goosens and Maren 2001; Amano et al. 2011). However, other sources suggest that the BA does not play a role in delay fear conditioning (e.g., Killcross et al. 1997; Amorapanth et al. 2000; Nader et al. 2001). Similarly, we observe no deficit in delay fear conditioning as a result of post-training administration of cycloheximide into the BA using either a 10- or three-trial conditioning procedure. Differences in procedure may account for discrepant results. Goosens and Maren (2001) utilized a pretraining lesion procedure in which rats received a large electrolytic lesion of the amygdala on one side, and a nucleus-specific neurotoxic lesion on the contralateral side. Lesions targeting the BA resulted in deficits to delay fear conditioning, but had no effect if the anterior portion of the BA was spared. It is possible that our cycloheximide infusions similarly spared the most anterior portion of the BA. Alternatively, it is also possible that while lesions of the BA disrupt delay conditioning, the formation of this association does not depend upon de novo protein synthesis in the BA. Finally, fibers of passage that would be destroyed with an electrolytic lesion of the BA are spared during cycloheximide infusion, which may account for differenc- es in the two manipulations. However, it is important to mention that Amano et al. (2011) found that a substantial portion of BA neurons acquire excitatory responses to the CS during delay fear conditioning. Specifically, basomedial responses persist long after CS-offset, suggesting that they are not merely passive relays of rapidly adapting LA input. Additionally, they demonstrated that pretesting muscimol inactivation of the entire BA (including medial and lateral portions) attenuated freezing to the tone. This result strengthens the possibility that our cycloheximide infusions may have partially spared the BA.

Post-training BA infusions of cycloheximide produced a deficit in contextual fear conditioning in trace, as well as three-trial delay, conditioned animals. This was an expected result, as there is strong evidence that the BA is critical for contextual fear conditioning (Muller et al. 1997; Goosens and Maren 2001; Vlachos et al. 2011). However, no deficits were observed in contextual fear conditioning in 10-trial delay conditioned animals. This is most likely due to a floor effect, as both vehicle- and cycloheximide-infused delay animals froze at relatively low levels during the context test (see Fig. 2D). In a 10-trial delay conditioning procedure, it is reasonable to expect that conditioning to the context would be relatively weak since the associative strength of the tone is very strong.

Protein synthesis inhibitors are sometimes criticized for their nonspecific effects, such as cell death and catecholamine synthesis inhibition (Flexner and Goodman 1975; Radulovic and Tronson 2008; Rudy 2008). However, there is an established history of experiments examining amygdalar contributions to delay fear conditioning using protein synthesis inhibitors as amnesic agents, (e.g., Bailey et al. 1999; Schafe and LeDoux 2000; Maren et al. 2003; Kwapis et al. 2011). As little is known about amygdalar contributions to trace fear conditioning, it is a sound practice to use a broad approach rather than attempting to target a more specific signaling cascade. Cycloheximide is a less commonly used protein synthesis inhibitor than anisomycin, but it is sometimes preferred as it is easier to keep in solution. There is no evidence to suggest that it is less effective than other protein synthesis inhibitors (e.g., Milekic et al. 2006; Lai et al. 2008), and it has been successfully used in the amygdala as an amnesic agent in a number of studies (e.g., Berman et al. 1978; Duvarci et al. 2005; Pedroso et al. 2013), including the present study.

Though the diffusion extent of cycloheximide was not measured for the present experiments, evidence suggests diffusion was confined to the targeted subnucleus. A labeling study carried out by Parsons et al. (2006) demonstrated that another protein synthesis inhibitor, anisomycin, remained within the boundaries of the amygdala using a similar infusion size $(0.5 \mu \mathrm{L})$. Similarly, Amano et al. (2011) administered $0.3 \mu \mathrm{L}$ of $0.5 \mathrm{mM}$ fluorescent muscimol dissolved in aCSF targeting the lateral or medial portion of the BA. Imaging revealed that infusions targeting the individual basal subnuclei were reasonably well-contained $10 \mathrm{~min}$ after infusion time. While inactivation of either subnucleus alone had no effect, combined inactivation of the basal medial and basal lateral nuclei resulted in a deficit in delay fear conditioning learning. Finally, the present pattern of behavioral results reveals differential involvement of LA and BA as a function of training condition (delay vs. trace). This suggests that our cycloheximide infusions were relatively well contained within the targeted amygdala nucleus. Protein synthesis in the lateral amygdala has been shown to be critical for the consolidation of delay fear conditioning (e.g., Schafe and LeDoux 2000; Kwapis et al. 2011), and LA, but not BA, infusions of cycloheximide disrupted three-trial delay conditioning in the present experiments.

In conclusion, the present data support a role for the BLA in trace, delay, and contextual fear conditioning. Trace fear conditioning appears to be more dependent upon BA processing, since 
infusions of cycloheximide into this region, but not into the LA, disrupt consolidation of trace fear memories. However, it is worth noting the trend toward a deficit following cycloheximide infusions into LA. Consistent with previous findings, delay fear conditioning appears to be more dependent upon LA processing, since infusions of cycloheximide into this region, but not into the BA, disrupt consolidation of delay fear memories (at least when using a three-trial delay procedure). This dissociation is strengthened by a recent finding showing that expression of the immediate early gene, activity-regulated cytoskeleton-associated protein (Arc/ Arg3.1), is elevated in BA, but not LA, following trace fear conditioning (Chau et al. 2013).

\section{Materials and Methods}

\section{Animals}

All rats were experimentally naïve Long-Evans rats. Thirty-six female rats were bred in-house for use in Experiment 1. One hundred two male rats were purchased from Harlan Laboratories (Indianapolis, IN) for use in Experiments 2, 4, and 5. Fifty male rats were bred in-house for use in Experiment 3 . All rats were pairhoused in standard colony caging on a 12:12-h light:dark cycle and given ad libitum access to food and water. The rats were handled for $1 \mathrm{~min}$ per day for five consecutive days prior to surgery. All procedures were performed during the light cycle and were approved by the Miami University Institutional Animal Care and Use Committee in accordance with the NIH Guidelines for the Care and Use of Experimental Animals.

\section{Lesion surgery}

Rats were anesthetized with 5\% isoflurane (Vedco) in an induction chamber. They were placed in a standard stereotaxic instrument and maintained on $2 \%-3 \%$ isoflurane at $1 \mathrm{~L} / \mathrm{min}$. Body temperature was maintained on a heating pad located under the rat throughout surgery. The scalp was shaved, incised, and retracted. The head was leveled by equating bregma and $\lambda$ in the horizontal plane. Stainless steel tubing (28 gauge; Plastics One) connected to $10 \mu \mathrm{L}$ Hamilton syringes using clear polyethylene tubing (PE20) were lowered into the brain bilaterally targeting the basolateral amygdala. For coordinates, see Table 1. N-Methyl-D-aspartate (NMDA; $20 \mu \mathrm{g} / \mu \mathrm{L}$; Sigma-Aldrich) was infused into each site $(0.1 \mu \mathrm{L} /$ site $)$, followed by a 2-min diffusion time. Following the last infusion, the skull was dried and the scalp was closed using stainless steel wound clips. Sham surgery consisted of the incision, retraction, and closing of the scalp; no infusions of any kind were administered. At the end of surgery, the rats were given two subcutaneous injections: $3 \mathrm{~mL}$ of $0.9 \%$ saline for rehydration and $5 \mathrm{mg} / \mathrm{kg} / \mathrm{mL}$ of Rimadyl to reduce pain and inflammation. Following surgery, the rats were placed into a recovery cage on a heating pad until they fully awoke from anesthesia. Post-operative care was performed for five consecutive days after surgery. Rimadyl ( $5 \mathrm{mg} / \mathrm{kg} / \mathrm{mL}$; s.c.) was administered at 24 and $48 \mathrm{~h}$ postsurgery. Saline $(0.9 \% ; 3 \mathrm{~mL}$; s.c.) was given as needed for signs of dehydration.

Table 1. Lesion coordinates used in Experiment 1

\begin{tabular}{lcc}
\hline Anterior/posterior & Medial/lateral & Dorsal/ventral \\
\hline-2.3 & \pm 5.0 & -8.0 \\
& & -8.4 \\
-3.1 & \pm 5.2 & -8.8 \\
-3.8 & \pm 5.3 & -8.4 \\
& & -8.8 \\
& & -8.8 \\
\hline
\end{tabular}

All measurements are relative to bregma. Infusion volumes were $0.1 \mu \mathrm{L}$ per site with a 2-min diffusion time.

\section{Cannulation surgery}

Rats were anesthetized and skulls were leveled as described previously. Guide cannulae (22 gauge; Plastics One) were lowered into the brain bilaterally targeting the BA or LA using the following Coordinates: $\mathrm{BA}(\mathrm{AP}-3.0 \mathrm{~mm}, \mathrm{ML} \pm 5.3 \mathrm{~mm}, \mathrm{DV}-7.9 \mathrm{~mm}$ ); LA (AP $-2.9 \mathrm{~mm}, \mathrm{ML} \pm 5.0 \mathrm{~mm}, \mathrm{DV}-6.8 \mathrm{~mm}$ ) relative to bregma (Paxinos and Watson 1998). Four skull screws and dental acrylic were used to secure the guide cannulae within the skull. Obturators were placed into the guide cannulae to prevent debris from entering. Following surgery, post-operative care was administered as described above.

\section{Behavioral apparatus}

Animals were fear conditioned and context tested in four identical Context A chambers $(32.4 \times 25.4 \times 21.6 \mathrm{~cm}$; MED-Associates, Inc.). The ceiling and front door of each chamber were made of clear Plexiglas, the back wall was white Plexiglas and the two side walls were aluminum. The floor consisted of 19 equally spaced stainless steel rods. The grid floor in each chamber was wired to a shock generator and scrambler (MED-Associates, Inc.). The conditioning chambers were wiped down with an odorless $5 \%$ sodium hydroxide solution and scented with 50\% vanilla flavor (Meijer) solution. The chamber was brightly lit (125 lux) by a light box located above the conditioning chamber.

Animals were tested for freezing to tone in Context B. These chambers $(32.4 \times 25.4 \times 21.6 \mathrm{~cm}$; MED-Associates, Inc. $)$ were located in a different experimental room and were distinct from Context A. They consisted of a Plexiglas floor and a Plexiglas equilateral triangular insert. The context was cleaned and scented with a $1 \%$ glacial acetic acid solution. The light box above the chamber provided near-infrared lighting (0 lux).

The rats were continuously monitored by a progressive scan video camera with a visible light filter (VID-CAM-MONO-2A; MED-Associates, Inc.) connected to a computer in the experimental room running Video-Freeze software (MED-Associates, Inc.) designed for automated assessment of defensive freezing (see Anagnostaras et al. 2010).

\section{Infusions}

Injectors (28 gauge) were connected to $10 \mu \mathrm{L}$ Hamilton syringes using clear polyethylene tubing (PE20). The injectors were inserted into the cannulae so that they extended $1 \mathrm{~mm}$ below the guide. All infusions were delivered via an infusion pump (KD Scientific, Inc.) at a rate of $0.1 \mu \mathrm{L} / \mathrm{min}$ for $5 \mathrm{~min}$. Rats were placed in plastic bins with $\sim 3 \mathrm{~cm}$ standard bedding during infusions, and were left for $4 \mathrm{~min}$ following infusion to allow for diffusion. In Experiments $2-5$, the protein synthesis inhibitor, cycloheximide $(50 \mathrm{mg} / \mathrm{mL}$; Sigma-Aldrich, Inc.), was dissolved in 50\%DMSO/50\%aCSF and infused bilaterally into the BA or LA. In control rats, the vehicle was infused into the same location at the same rate and duration.

\section{Procedure Experiment 1}

Rats were randomly assigned to one of four conditions: (1) trace conditioned rats that received pretraining sham surgeries; (2) trace conditioned rats that received pretraining BLA lesions; (3) delay conditioned rats that received pretraining sham surgeries; and (4) delay conditioned rats that received pretraining BLA lesions. Trace conditioned rats were given a 120 -sec acclimation period, followed by 10 trials consisting of a 16-sec tone $(2 \mathrm{kHz})$, followed by a 28 -sec trace interval and then a 2 -sec footshock $(0.9 \mathrm{~mA})$. Delay conditioned rats were given a 120 -sec acclimation period, followed by 10 trials consisting of a 16 -sec tone $(2 \mathrm{kHz})$, coterminating with a 2 -sec footshock $(0.9 \mathrm{~mA})$. The intertrial interval (ITI) was $256 \mathrm{sec}$ (tone onset to tone onset). The session durations for trace and delay conditioning were equal. On day 2 , all rats were tested for context freezing in Context A during an 8-min session. Freezing is defined as the absence of all movement except that necessary for respiration (e.g., Fanselow 1980), with significant muscle tone. On day 3 , rats underwent tone testing in a novel 
context (Context B), which consisted of a 180-sec baseline period, followed by three discrete tone presentations separated by $256 \mathrm{sec}$.

\section{Procedure Experiment 2}

Rats were randomly assigned to one of five conditions: (1) unpaired controls that received post-training vehicle infusions; (2) trace conditioned rats that received post-training vehicle infusions; (3) trace conditioned rats that received post-training cycloheximide infusions; (4) delay conditioned rats that received post-training vehicle infusions; and (5) delay conditioned rats that received post-training cycloheximide infusions. The procedure was identical to Experiment 1 except that an unpaired training condition was included. The unpaired conditioned rats were given a 120 -sec acclimation period, followed by 10 tones and then 10 footshocks, or vice versa. The interstimulus interval (ISI) was $130 \mathrm{sec}$ (stimulus onset to stimulus onset). Session duration was equal to that of trace and delay conditioned animals. Additionally, rats underwent pretraining cannulation surgery targeting the BA, and received immediate post-training infusions of vehicle or cycloheximide.

\section{Procedure Experiment 3}

Rats were randomly assigned to one of four conditions: (1) trace conditioned rats that received post-training vehicle infusions; (2) trace conditioned rats that received post-training cycloheximide infusions; (3) delay conditioned rats that received posttraining vehicle infusions; and (4) delay conditioned rats that received post-training cycloheximide infusions. The procedure was identical to Experiment 2 except that an unpaired training condition was not included, and post-training infusions targeted the LA.

\section{Procedure Experiment 4}

Rats were randomly assigned to one of two conditions: (1) delay conditioned rats that received post-training vehicle infusions and (2) delay conditioned rats that received post-training cycloheximide infusions. Delay conditioning consisted of three tonefootshock trials using a 16-sec tone coterminating with a 2-sec footshock. The ITI was $60 \mathrm{sec}$ and the session duration was 6 min, $48 \mathrm{sec}$. Infusions targeted the BA.

\section{Procedure Experiment 5}

Rats were randomly assigned to one of two conditions: (1) delay conditioned rats that received post-training vehicle infusions and (2) delay conditioned rats that received post-training cycloheximide infusions. The procedure was identical to that of Experiment 4, except that infusions targeted the LA.

\section{Histology}

\section{GFAP and NeuN immunofluorescence staining}

At the end of behavioral testing in Experiment 1, rats were anesthetized with $0.2 \mathrm{~mL}$ Euthasol i.p. (Virbac Animal Health, Inc.; $390 \mathrm{mg}$ pentobarbital sodium $+50 \mathrm{mg}$ phenytoin sodium per $\mathrm{mL}$ ). The rats were perfused intracardially with a phosphate buffered saline solution followed by $0.4 \%$ paraformaldehyde. Brains were removed and placed into $0.4 \%$ paraformaldehyde. One day later, each brain was transferred into a 30\% glycerol in phosphate buffered saline solution. Brains were frozen and sliced on a cryostat in $40 \mu \mathrm{m}$ coronal sections. Sections were stored in $0.1 \%$ sodium azide in well plates until immunohistochemical staining. Antibodies were directed against: (1) the astrocyte marker glial fibrillary acidic protein (GFAP) and (2) the neuronal nuclei marker NeuN.

Following a series of washes in $0.1 \mathrm{M}$ PBS, sections were incubated overnight in $0.1 \mathrm{M}$ PBS-0.2\% Triton-X solution, blocked with normal donkey serum, and then incubated for $48 \mathrm{~h}$ at $4^{\circ} \mathrm{C}$ in primary antibody: Mouse anti-NeuN (Millipore MAB377) and chicken anti-GFAP (Abcam AB64674) diluted in 0.1 M PBS.
Following a series of rinses, sections were incubated for $2 \mathrm{~h}$ in AlexaFluor conjugated antibodies directed toward the primary host antibody (Alexa Fluor 555 Donkey Antimouse, Life Technologies A-31570; Alexa Fluor 488 Donkey AntiChicken, Jackson Immuno 703-545-155). Sections then were rinsed, mounted on slides, and coverslipped using fluorescent mounting medium with DAPI (Vectashield, Vector Labs H-1200). Images were captured using an Olympus AX-70 Research System microscope.

\section{Cresyl violet staining}

At the end of behavioral testing in Experiments 2-5, the rats were anesthetized with $0.2 \mathrm{~mL}$ Euthasol i.p. (Virbac Animal Health, Inc.; $390 \mathrm{mg}$ pentobarbital sodium $+50 \mathrm{mg}$ phenytoin sodium per $\mathrm{mL}$ ). To visualize infusion locations, rats were administered $0.5 \mu \mathrm{L}$ of Cresyl violet acetate $(10 \%$ in distilled water; SigmaAldrich, Inc.) into each site using the same rate and duration of drug infusions. The rats were perfused intracardially with $0.9 \%$ saline followed by $10 \%$ formalin. Brains were removed and placed into $10 \%$ formalin. One day later, each brain was transferred into a $10 \%$ formalin $/ 30 \%$ sucrose solution. Brains were frozen and sliced on a cryostat in $50 \mu \mathrm{m}$ coronal sections. Every fourth slice through the amygdala was collected and mounted onto microscope slides. The brain slices were stained with $0.5 \%$ thionin (Sigma-Aldrich, Inc.) and coverslipped. Infusion locations were verified using a light microscope by an observer who was blind to the condition and behavior of each animal.

\section{Data analysis}

All statistics were calculated using SPSS version 20.0. In Experiments $1-3$, factorial (training and infusion or training and surgery) and repeated-measures (tone number and trace interval number) analyses of variance (ANOVAs) were conducted to analyze the percentage of time spent freezing during the baseline, tone, trace interval, and context periods. In Experiments 4-5, $t$-tests were conducted to analyze the percentage of time spent freezing during the baseline, tone, and context periods. A priori planned comparisons between groups were performed using Fisher's LSD. A critical value $\alpha=0.05$ was used for all analyses.

\section{Acknowledgments}

We thank Kevin D. Lash and Samantha L. Hagerty for their contributions to the project. We also thank Matt Duley of the Center for Advanced Microscopy and Imaging at Miami University for his assistance with imaging. This work was supported by R15 MH100689 and a grant from the Miami University College of Arts and Science (J.J.Q.). Additional support was provided by Miami University Undergraduate Research Awards (E.A.F., Kevin D. Lash, and A.F.P), Miami University Undergraduate Summer Scholar Awards (E.A.F. and A.F.P.), Miami University Undergraduate Dean Scholar Awards (E.C.T. and E.A.F.), and a Miami University DUOS Award (E.A.F. and D.E.K.).

\section{References}

Amano T, Duvarci S, Popa D, Paré D. 2011. The fear circuit revisited: contributions of the basal amygdala nuclei to conditioned fear. $J$ Neurosci 31: 15481-15489.

Amorapanth P, LeDoux JE, Nader K. 2000. Different lateral amygdala outputs mediate reactions and actions elicited by a fear-arousing stimulus. Nat Neurosci 3: 74-79.

Anagnostaras SG, Wood SC, Shuman T, Cai DJ, Leduc AD, Zurn KR, Zurn JB, Sage JR, Herrera GM. 2010. Automated assessment of Pavlovian conditioned freezing and shock reactivity in mice using the video freeze system. Front Behav Neurosci doi: 10.3389/fnbeh.2010.00158.

Bailey DJ, Kim JJ, Sun W, Thompson RF, Helmstetter FJ. 1999. Acquisition of fear conditioning in rats requires the synthesis of mRNA in the amygdala. Behav Neurosci 113: 276-282.

Barot SK, Chung A, Kim JJ, Bernstein IL. 2009. Functional imaging of stimulus convergence in amygdalar neurons during Pavlovian fear conditioning. PLoS One 4: e6156. 
Ben Mamou C, Gamache K, Nader K. 2006. NMDA receptors are critical for unleashing consolidated auditory fear memories. Nat Neurosci 9: $1237-1239$.

Berman R, Kesner R, Partlow L. 1978. Passive avoidance impairment in rats following cycloheximide injection into the amygdala. Brain Res 158: $171-188$.

Chau LS, Prakapenka A, Fleming SA, Davis AS, Galvez R. 2013. Elevated Arc/Arg 3.1 protein expression in the basolateral amygdala following auditory trace-cued fear conditioning. Neurobiol Learn Mem 106: $127-133$.

Chowdhury N, Quinn JJ, Fanselow MS. 2005. Dorsal hippocampus involvement in trace fear conditioning with long, but not short, trace intervals in mice. Behav Neurosci 119: 1396-1402.

Davis M. 1997. Neurobiology of fear responses: the role of the amygdala. $J$ Neuropsychiatry Clin Neurosci 9: 382-402.

Davis M. 2006. Neural systems involved in fear and anxiety measured with fear-potentiated startle. Am Psychol 61: 741-756.

Duvarci S, Nader K, LeDoux JE. 2005. Activation of extracellular signal-regulated kinase- mitogen-activated protein kinase cascade in the amygdala is required for memory reconsolidation of auditory fear conditioning. Eur J Neurosci 21: 283-289.

Fanselow MS. 1980. Conditional and unconditional components of post-shock freezing. Pavlov J Biol Sci 15: 177-182.

Fanselow MS, LeDoux JE. 1999. Why we think plasticity underlying Pavlovian fear conditioning occurs in the basolateral amygdala. Neuron 23: $229-232$.

Flexner L, Goodman RH. 1975. Studies on memory: inhibitors of protein synthesis also inhibit catecholamine synthesis. Proc Natl Acad Sci 72: $4660-4663$.

Gale GD, Anagnostaras SG, Godsil BP, Mitchell S, Nozawa T, Sage JR, Wiltgen B, Fanselow MS. 2004. Role of the basolateral amygdala in the storage of fear memories across the adult lifetime of rats. J Neurosci $\mathbf{2 4}$ $3810-3815$.

Gilmartin MR, Helmstetter FJ. 2010. Trace and contextual fear conditioning require neural activity and NMDA receptor-dependent transmission in the medial prefrontal cortex. Learn Mem 17: 289-296.

Gilmartin MR, McEchron MD. 2005a. Single neurons in the dentate gyrus and CA1 of the hippocampus exhibit inverse patterns of encoding during trace fear conditioning. Behav Neurosci 119: 164-179.

Gilmartin MR, McEchron MD. 2005b. Single neurons in the medial prefrontal cortex of the rat exhibit tonic and phasic coding during trace fear conditioning. Behav Neurosci 119: 1496-1510.

Gilmartin MR, Kwapis JL, Helmstetter FJ. 2012. Trace and contextual fear conditioning are impaired following unilateral microinjection of muscimol in the ventral hippocampus or amygdala, but not the medial prefrontal cortex. Neurobiol Learn Mem 97: 452-464.

Goosens KA, Maren S. 2001. Pretraining NMDA receptor blockade in the basolateral complex, but not the central nucleus, of the amygdala prevents savings of conditional fear. Behav Neurosci 117: 738-750

Han CJ, O'Tuathaigh CM, van Trigt L, Quinn JJ, Fanselow MS, Mongeau R, Anderson DJ. 2003. Trace but not delay fear conditioning requires attention and the anterior cingulate cortex. Proc Natl Acad Sci 100 13087-13092.

Killcross S, Robbins TW, Everitt BJ. 1997. Different types of fear-conditioned behaviour mediated by separate nuclei within amygdala. Nature 388: $377-380$.

Kwapis JL, Jarome TJ, Schiff JC, Helmstetter FJ. 2011. Memory consolidation in both trace and delay fear conditioning is disrupted by intra-amygdala infusion of the protein synthesis inhibitor anisomycin. Learn Mem 18: 728-732.

Lai YT, Fan HY, Cherng CG, Chiang CY, Kao GS, Yu L. 2008. Activation of amygdaloid PKC pathway is necessary for conditioned cues-provoked cocaine memory performance. Neurobiol Learn Mem 90: 164-170.

LeDoux JE. 1993. Emotional memory systems in the brain. Behav Brain Res 58: $69-79$

LeDoux JE, Iwata J, Cicchetti P, Reis DJ. 1988. Different projections of the central amygdaloid nucleus mediate autonomic and behavioral correlates of conditioned fear. I Neurosci 8: 2517-2529.

Lee HJ, Choi JS, Brown TH, Kim JJ. 2001. Amygdalar NMDA receptors are critical for the expression of multiple conditioned fear responses. $J$ Neurosci 21: 4116-4124.

Maren S. 2008. Pavlovian fear conditioning as a behavioral assay for hippocampus and amygdala function: cautions and caveats. Eur $J$ Neurosci 28: 1661-1666.

Maren S, Ferrario CR, Corcoran KA, Desmond TJ, Frek KA. 2003. Protein synthesis in the amygdala, but not the auditory thalamus, is required for consolidation of Pavlovian fear conditioning in rats. Eur J Neurosci 18: $3080-3088$

McEchron MD, Bouwmeester H, Tseng W, Weiss C, Disterhoft JF. 1998. Hippocampectomy disrupts auditory trace fear conditioning and contextual fear conditioning in the rat. Hippocampus 8: 638-646.
Milekic MH, Brown SD, Castellini C, Alberini CM. 2006. Persistent disruption of an established morphine conditioned place preference. J Neurosci 26: 3010-3020.

Muller J, Corodimas KP, Fridel Z, LeDoux JE. 1997. Functional inactivation of the lateral and basal nuclei of the amygdala by muscimol infusion prevents fear conditioning to an explicit conditioned stimulus and to contextual stimuli. Behav Neurosci 111: 683-691.

Nader K, Majidishad P, Amorapanth P, LeDoux JE. 2001. Damage to the lateral and central, but not other, amygdaloid nuclei prevents the acquisition of auditory fear conditioning. Learn Mem 8: $156-163$.

Pape H, Pare D. 2010. Plastic synaptic networks of the amygdala for the acquisition, expression, and extinction of conditioned fear. Physiol Rev 90: $419-463$.

Parsons RG, Gafford GM, Baruch DE, Riedner BA, Helmstetter FJ. 2006 Long-term stability of fear memory depends on the synthesis of protein but not mRNA in the amygdala. Eur J Neurosci 23: 1853-1859.

Paxinos G, Watson C. 1998. The rat brain in stereotaxic coordinates, 4th ed. Academic Press, San Diego, CA.

Pedroso TR, Jobim PFC, Carvalho LM, Christoff RR, Maurmann N, Reolon GK, Werenicz A, Roesler R. 2013. Inhibition of protein synthesis or mTOR in the basolateral amygdala blocks retrieval-induced memory strengthening. J Neural Transm 120: 1525-1531.

Ponnusamy R, Poulos AM, Fanselow MS. 2007. Amygdala-dependent and amygdala-independent pathways for contextual fear conditioning. Neuroscience 147: 919-927.

Quinn JJ, Ommen SS, Morrison GE, Fanselow MS. 2002. Post-training excitotoxic lesions of the dorsal hippocampus attenuate forward trace, backward trace, and delay fear conditioning in a temporally specific manner. Hippocampus 12: 495-504.

Quinn JJ, Loya F, Ma QD, Fanselow MS. 2005. Dorsal hippocampus NMDA receptors differentially mediate trace and contextual fear conditioning. Hippocampus 15: 665-674.

Quinn JJ, Wied HM, Ma QD, Tinsley MR, Fanselow MS. 2008. Dorsal hippocampus involvement in delay fear conditioning depends upon the strength of the tone-footshock association. Hippocampus 18: $640-654$.

Quinn JJ, Wied HM, Liu D, Fanselow MS. 2009. Post-training excitotoxic lesions of the dorsal hippocampus attenuate generalization in auditory delay fear conditioning. Eur J Neurosci 29: 1692-1700.

Quinn JJ, Pittenger C, Lee AS, Pierson JL, Taylor JR. 2013. Striatum-dependent habits are insensitive to both increases and decreases in reinforcer value in mice. Eur I Neurosci 37: 1012-1021.

Radulovic J, Tronson NC. 2008. Protein synthesis inhibitors, gene superinduction and memory: too little or too much protein? Neurobiol Learn Mem 89: 212-218.

Raybuck JD, Lattal KM. 2011. Double dissociation of amygdala and hippocampal contributions to trace and delay fear conditioning. PLoS One 6: e15982.

Rudy J. 2008. Is there a baby in the bathwater? Maybe: some methodological issues for the de novo protein synthesis hypothesis. Neurobiol Learn Mem 89: 219-224.

Rudy JW, O'Reilly RC. 1999. Contextual fear conditioning, conjunctive representations, pattern completion, and the hippocampus. Behav Neurosci 113: 867-880

Sananes CB, Davis M. 1992. N-methyl-D-aspartate lesions of the lateral and basolateral nuclei of the amygdala block fear-potentiated startle and shock sensitization of startle. Behav Neurosci 106: 72-80.

Schafe GE, LeDoux JE. 2000. Memory consolidation of auditory pavlovian fear conditioning requires protein synthesis and protein kinase $\mathrm{A}$ in the amygdala. J Neurosci 20: RC96.

Viviani D, Charlet A, van den Burg E, Robinet C, Hurni N, Abatis M, Magara F, Stoop R. 2011. Oxytocin selectively gates fear responses through distinct outputs from the central amygdala. Science 333: 104-107.

Vlachos I, Herry C, Lüthi A, Aertsen A, Kumar A. 2011. Context-dependent encoding of fear and extinction memories in a large-scale network model of the basal amygdala. PLoS Comput Biol 7: e1001104.

Wilensky AE, Schafe GE, Kristensen MP, LeDoux JE. 2006. Rethinking the fear circuit: the central nucleus of the amygdala is required for the acquisition, consolidation, and expression of Pavlovian fear conditioning. J Neurosci 26: 12387-12396.

Wiltgen BJ, Sanders MJ, Anagnostaras SG, Sage JR, Fanselow MS. 2006. Context fear learning in the absence of the hippocampus. J Neurosci 26: $5484-5491$.

Zimmerman JM, Rabinak CA, McLachlan IG, Maren S. 2007. The central nucleus of the amygdala is essential for acquiring and expressing conditional fear after overtraining. Learn Mem 14: 634-644.

Received February 24, 2014; accepted in revised form October 20, 2014. 


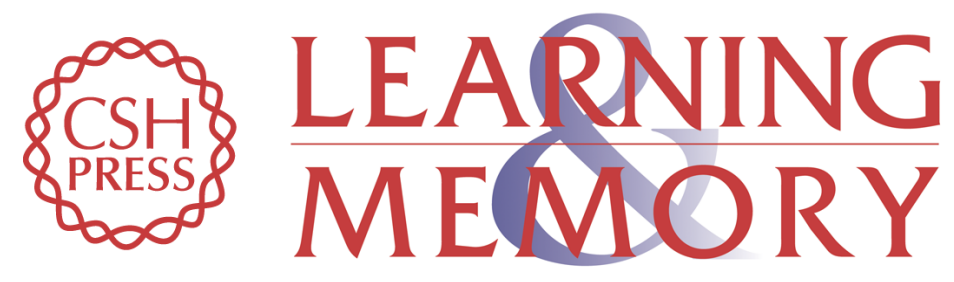

\section{The amygdala is critical for trace, delay, and contextual fear conditioning}

Daniel E. Kochli, Elaine C. Thompson, Elizabeth A. Fricke, et al.

Learn. Mem. 2015, 22:

Access the most recent version at doi:10.1101/Im.034918.114

References This article cites 54 articles, 15 of which can be accessed free at: http://learnmem.cshlp.org/content/22/2/92.full.html\#ref-list-1

Creative This article is distributed exclusively by Cold Spring Harbor Laboratory Press for the Commons License first 12 months after the full-issue publication date (see

http://learnmem.cshlp.org/site/misc/terms.xhtml). After 12 months, it is available under a Creative Commons License (Attribution-NonCommercial 4.0 International), as described at http://creativecommons.org/licenses/by-nc/4.0/.

Email Alerting Receive free email alerts when new articles cite this article - sign up in the box at the Service top right corner of the article or click here. 